\title{
Tailoring the Solid-state Fluorescence of BODIPY by Supramolecular Assembly with Polyoxometalates
}

Patricia Bolle, ${ }^{a}$ Tarik Benali, ${ }^{\mathrm{b}}$ Clotilde Menet, ${ }^{\mathrm{a}}$ Marin Puget, ${ }^{\mathrm{a}}$ Eric Faulques, ${ }^{\mathrm{a}}$ Jérome Marrot, ${ }^{\mathrm{b}}$ Pierre Mialane, ${ }^{b}$ Anne Dolbecq, ${ }^{b}$ Hélène Serier-Brault, ${ }^{a}$ Olivier Oms, ${ }^{b}$ and Rémi Dessapt ${ }^{a *}$

a Université de Nantes, CNRS, Institut des Matériaux Jean Rouxel, IMN, F-44000 Nantes, France

bUniversité Paris-Saclay, UVSQ, CNRS, Institut Lavoisier de Versailles, 78000, Versailles, France

Corresponding Author : remi.dessapt@cnrs-imn.fr, olivier.oms@uvsq.fr

\section{Electronic Supplementary Information}




\section{Physical Measurements.}

FT-IR spectra were recorded in the $4000-400 \mathrm{~cm}^{-1}$ range on a BRUKER Vertex equipped with a computer control using the OPUS software. Relative intensities are given after the wavenumber as vs = very strong, $\mathrm{s}=$ strong, $\mathrm{m}=$ medium, $\mathrm{w}=$ weak, $\mathrm{sh} .=$ shoulder, $\mathrm{br} .=$ broad. Elemental analyses of the solids were performed by the "Service Chromato-Masse Microanalyse, UMR 8076, Université Paris-Saclay" in Châtenay-Malabry (France) and the CRMPO (Centre de Mesures Physiques de l'Ouest) in Rennes. Nuclear magnetic resonance (NMR) spectra were recorded on a Bruker Advance 300 spectrometer operating at $300 \mathrm{MHz}$ for ${ }^{1} \mathrm{H}$ and $75 \mathrm{MHz}$ for ${ }^{13} \mathrm{C}$ nuclei at $\mathrm{T}=298 \mathrm{~K}$. Chemical shifts are expressed in parts per million (ppm) downfield from internal tetramethylsilane (TMS). The following abbreviations were used to explain the multiplicities: s, singlet; d, doublet; t, triplet; br, broad peaks; m, multiplet or overlapping peaks. Thermogravimetric analysis (TGA) were performed by flowing air with a heating and cooling rate of $5^{\circ} \mathrm{C} / \mathrm{min}$ on a SETARAM TG-DSC 111 between 20 and $800^{\circ} \mathrm{C}$. Electrospray ionization (ESI) mass spectra were recorded on a Xevo QTof WATERS (quadrupole-time-of-flight) instrument. The temperature of the source block was set to $120{ }^{\circ} \mathrm{C}$, and the desolvation temperature to $380{ }^{\circ} \mathrm{C}$. A capillary voltage of $2.5 \mathrm{kV}$ was used in the positive scan mode, and the cone voltage was set to $30 \mathrm{~V}$. Mass calibration was performed using a solution of sodium formate in water:acetonitrile (2:8) from m/z 100 to 1000. Sample solutions $10 \mu \mathrm{g} / \mathrm{mL}$ in acetonitrile were injected via syringe pump directly connected to the ESI source at a flow rate of $10 \mu \mathrm{L} / \mathrm{min}$. Solid-state optical properties were investigated by Diffuse Reflectance Spectroscopy of microcrystalline powders. Diffuse reflectance spectra were collected at room temperature on a finely ground sample with a Perkin-Elmer Lambda 1050 spectrometer equipped with a $150 \mathrm{~mm}$ diameter integrating sphere coated with Spectralon®, a highly reflecting fluoropolymer. Diffuse reflectance was measured from 250 to $1000 \mathrm{~nm}$ with a $2 \mathrm{~nm}$ step using Spectralon ${ }^{\circledR}$ as reference $(100 \%$ reflectance). The reflectance data were treated by a Kubelka-Munk transformation ${ }^{\mathrm{S} 1}$ to better determine the absorption thresholds. UV-vis absorption spectra in solution were obtained with the same Perkin-Elmer Lambda 1050 spectrometer. Room-temperature photoluminescence spectra were recorded on a Jobin-Yvon Fluorolog 3 fluorometer equipped with a photomultiplier (excitation source: $400 \mathrm{~W}$ Xe arc lamp and $150 \mathrm{~W}$ pulsed map for decay times). The emission spectra were corrected for detection and optical spectral response of the spectrofluorimeter and the excitation spectra were weighed for the spectral distribution of the lamp intensity using a photodiode reference detector. Time-resolved luminescence experiments were carried out with a regenerative amplified femtosecond Ti:Sapphire laser system (Spectra Physics Hurricane X) producing $100 \mathrm{fs}$ pulses at $800 \mathrm{~nm}$ with a repetitive rate of $1 \mathrm{kHz}$. The $800 \mathrm{~nm}$ line is frequency-doubled in a harmonic generator to an excitation wavelength of $400 \mathrm{~nm}(3.1 \mathrm{eV})$. The time-resolved emission spectra are recorded using a high dynamic range Hamamatsu C7700 streak camera of temporal resolution < 20 ps equipped with a readout CCD ORCAII camera Peltier cooled to $-60{ }^{\circ} \mathrm{C}$. The excitation density in the samples was adjusted with density filters to avoid sample photodegradation. Powder samples were pressed onto silica glass and studied in the solid state.

Crystal Structure. Intensity data collections were carried out with a Bruker Nonius X8 APEX 2 diffractometer equipped with a CCD bidimensional detector using Mo $\mathrm{K} \alpha$ 
monochromatized radiation $(\lambda=0.71073 \AA)$ for compounds $(\mathbf{1})_{2}\left[\mathbf{W}_{\mathbf{6}} \mathbf{O}_{\mathbf{1 9}}\right] \cdot \mathbf{2} \mathbf{C H} \mathbf{H}_{3} \mathbf{C N}(\mathrm{CCDC}$ 2062225), (1) ${ }_{\mathbf{2}}\left[\mathbf{W}_{\mathbf{6}} \mathbf{O}_{\mathbf{1 9}}\right]$ (CCDC 2062226), and (1) $\mathbf{4}_{\mathbf{4}}\left[\mathbf{M o}_{\mathbf{8}} \mathbf{O}_{\mathbf{2 6}}\right] \cdot \mathbf{D M F} \cdot \mathbf{H}_{\mathbf{2}} \mathbf{O}$ (CCDC 2062227). The absorption corrections were based on multiple and symmetry-equivalent reflections in the data set using the SADABS program ${ }^{\mathrm{S} 2}$ based on the method of Blessing. ${ }^{\mathrm{S} 3}$ The structures were solved by direct methods and refined by full-matrix least-squares using the SHELX-TL package. ${ }^{\mathrm{S} 4}$ The hydrogen atoms were theoretically located on the basis of the conformation of the supporting atoms. Crystallographic data are given in Table S1, and the complete data can be obtained free of charge via www.ccdc.cam.ac.uk/conts/ retrieving.html (or from the Cambridge Crystallographic Data Centre, 12 Union Road, Cambridge CB21EZ, U.K.; fax (44) 1223-336-033; email deposit@ ccdc.cam.ac.uk). 


\section{Experimental section}

Synthesis of 4,4-Difluoro-8-(4-(4-(N,N,N-trimethyl)aminobutoxy))phenyl-1,3,5,7tetramethyl-4-bora-3a,4a-diaza-s-indacene bromide ((1)Br).

(1)Br has been prepared by a slight modification (in the third step) of the previously reported procedure (Kim, T.-I.; Park, J.; Kim, Y., Chem. - Eur. J. 2011, 17 (43), 11978-11982, ref. 38 in the text) according to the following synthetic pathway displayed below:

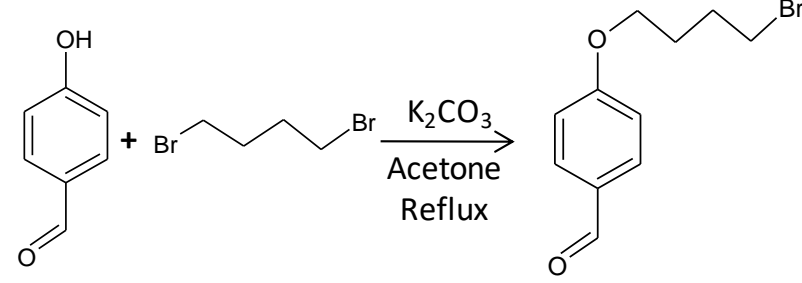

1) 2,4-dimethylpyrrole, TFA

2) $D D Q$

3) DiPEA

4) $\mathrm{BF}_{3} \cdot \mathrm{OEt}_{2}$
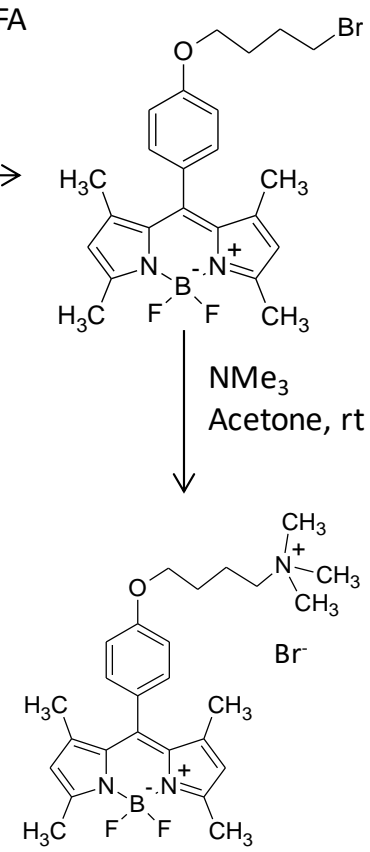

In the third synthesis step, trimethylamine ( $25 \mathrm{wt} . \%$ solution in water, $2.8 \mathrm{~mL}, 11 \mathrm{mmol}$ ) was added dropwise to a solution of the neutral BODIPY (50 mg, $0.105 \mathrm{mmol}$ ) in $6 \mathrm{~mL}$ of acetone. The resulting solution was then stirred at room temperature for $40 \mathrm{~h}$. After discarding a maximum of trimethylamine by bubbling nitrogen gas for $3 \mathrm{~h}$, the solvent was evaporated. The residue was then dissolved in acetone and water and the solution placed in a separating funnel along with methylene chloride. The aqueous phase was then recovered and evaporated. (1)Br was isolated as a reddish-brown solid and dried under vacuum (51 mg, $0.095 \mathrm{mmol}$, $90 \%$ yield).

${ }^{1} \mathrm{H}$ NMR (300 MHz, $\left.\mathrm{CDCl}_{3}\right): \delta=7.17(\mathrm{~d}, 2 \mathrm{H}, \mathrm{J}=8.5 \mathrm{~Hz}), 7.01(\mathrm{~d}, 2 \mathrm{H}, \mathrm{J}=8.5 \mathrm{~Hz}), 5.98(\mathrm{~s}$, $2 \mathrm{H}), 4.10(\mathrm{t}, 2 \mathrm{H}), 3.80(\mathrm{~m}, 2 \mathrm{H}), 3.51(\mathrm{~s}, 9 \mathrm{H}), 2.55(\mathrm{~s}, 6 \mathrm{H}), 2.07(\mathrm{~m}, 2 \mathrm{H}), 1.97(\mathrm{~m}, 2 \mathrm{H}), 1.43(\mathrm{~s}$, $6 \mathrm{H})$.

${ }^{13} \mathrm{C}$ NMR $\left(75 \mathrm{MHz}, \mathrm{CDCl}_{3}\right): \delta=159.1,155.3,143.1,141.6,131.8,129.3,127.4,121.2$, $115.0,77.2,66.8,66.6,53.6,29.7,26.0,20.4,14.7,14.6$. 
Figure S1. ${ }^{1} \mathrm{H}$ NMR $\left(\mathrm{CDCl}_{3}\right)$ spectrum of (1)Br.

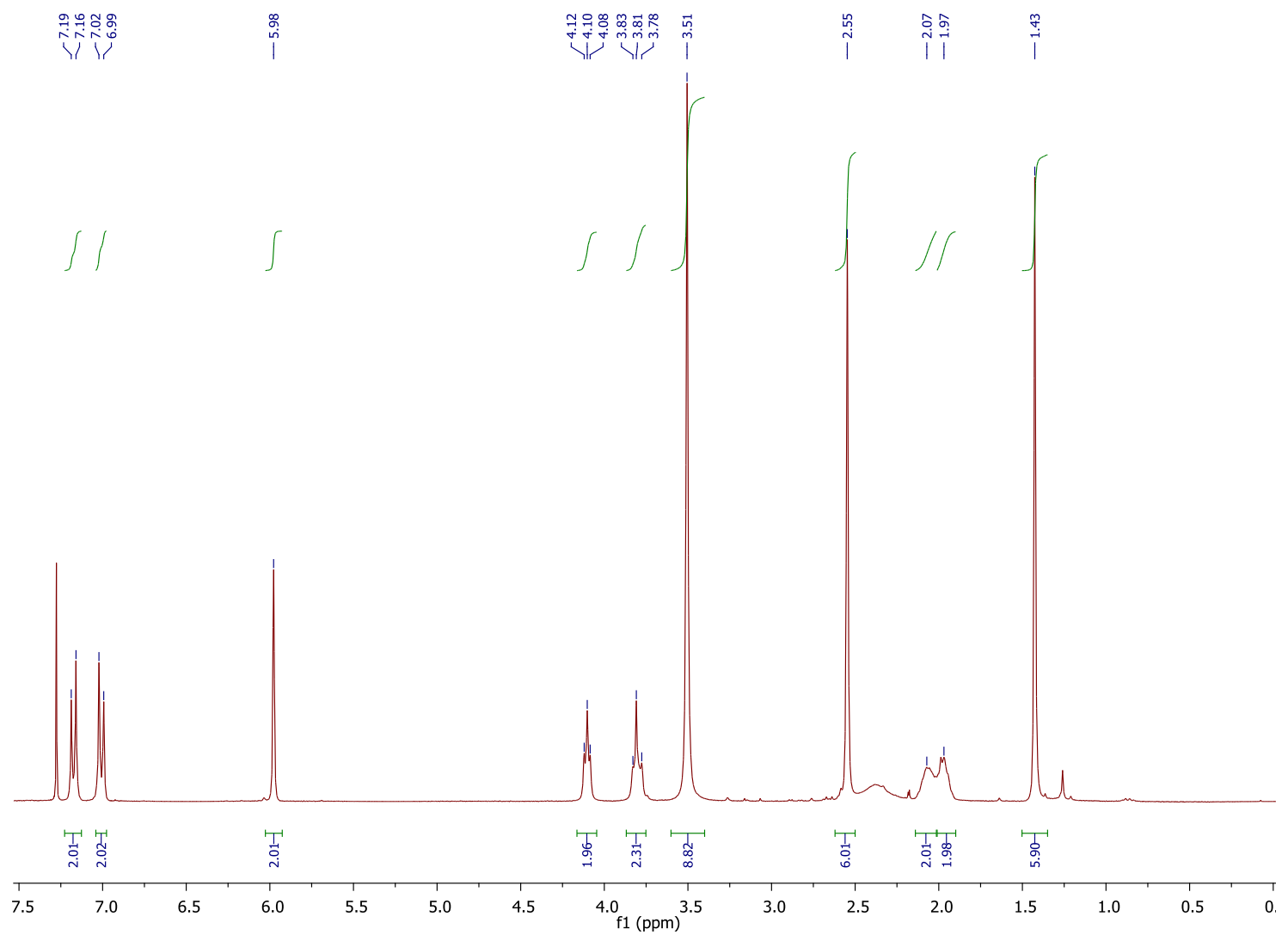

Figure S2. ESI/MS spectrum of (1)Br

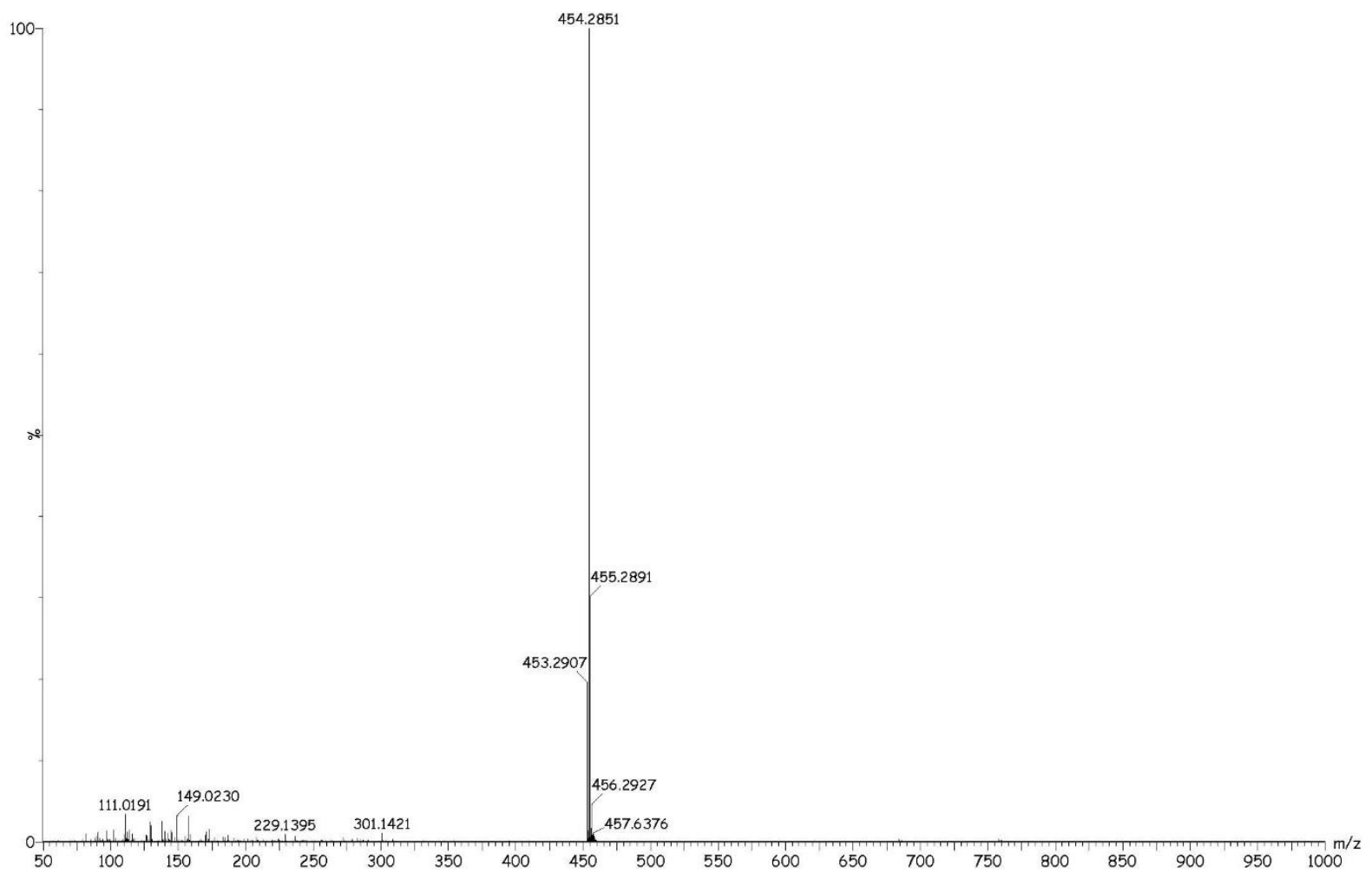


Figure S3. FT-IR spectra of (a) (1)Br, (b) (1) $)_{2}\left[\mathbf{W}_{\mathbf{6}} \mathbf{O}_{\mathbf{1 9}}\right] \cdot \mathbf{2} \mathbf{C H}_{3} \mathbf{C N}$ and (c) $\left(\mathrm{NBu}_{4}\right)_{2}\left[\mathrm{~W}_{6} \mathrm{O}_{19}\right]$. Lines denoted by an asterisk are attributed to the vibration modes of the $\mathrm{NBu}_{4}{ }^{+}$cations.

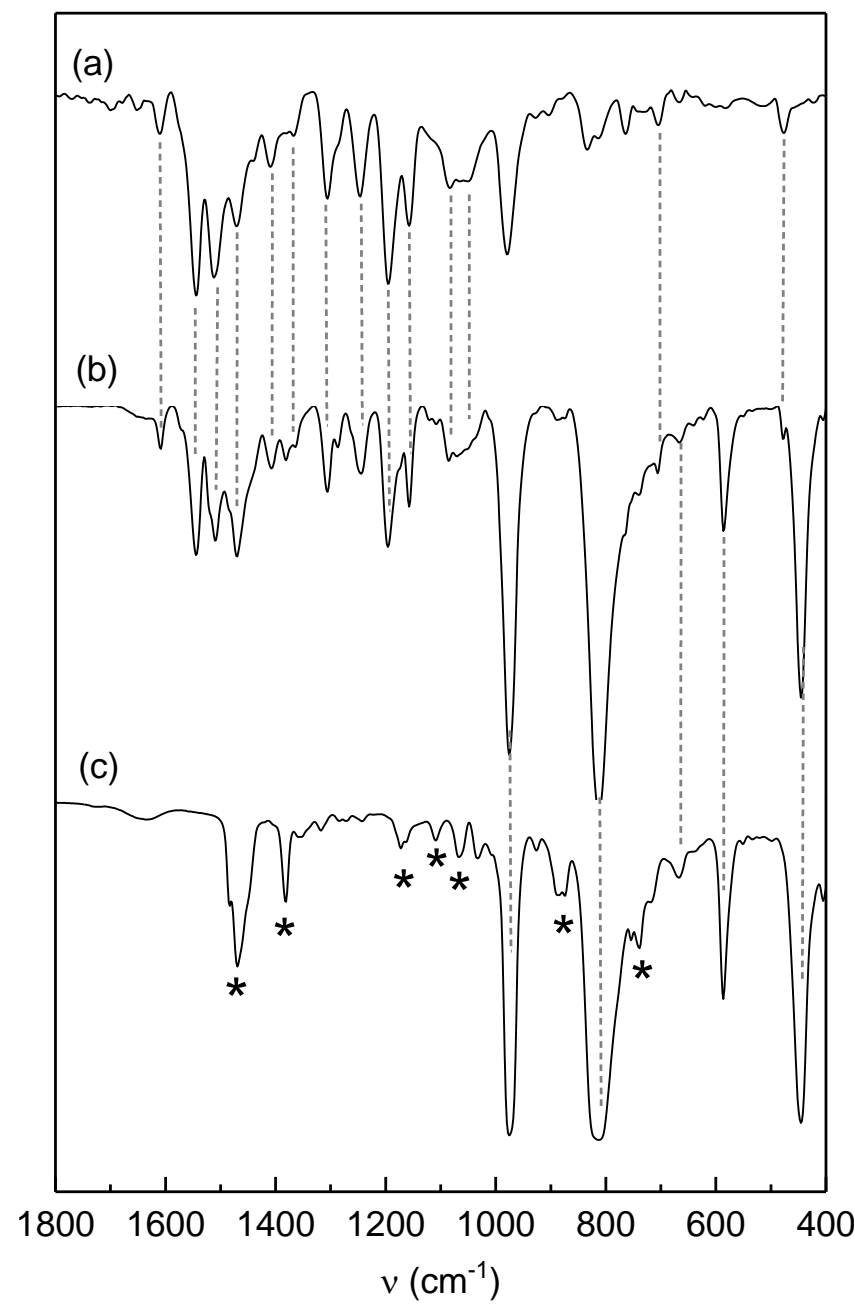


Figure S4. FT-IR spectra of (a) (1)Br, (b) (1) $)_{2}\left[\mathbf{W}_{\mathbf{6}} \mathbf{O}_{19}\right]$ and (c) $\left(\mathrm{NBu}_{4}\right)_{2}\left[\mathrm{~W}_{6} \mathrm{O}_{19}\right]$. Lines denoted by an asterisk are attributed to the vibration modes of the $\mathrm{NBu}_{4}{ }^{+}$cations.

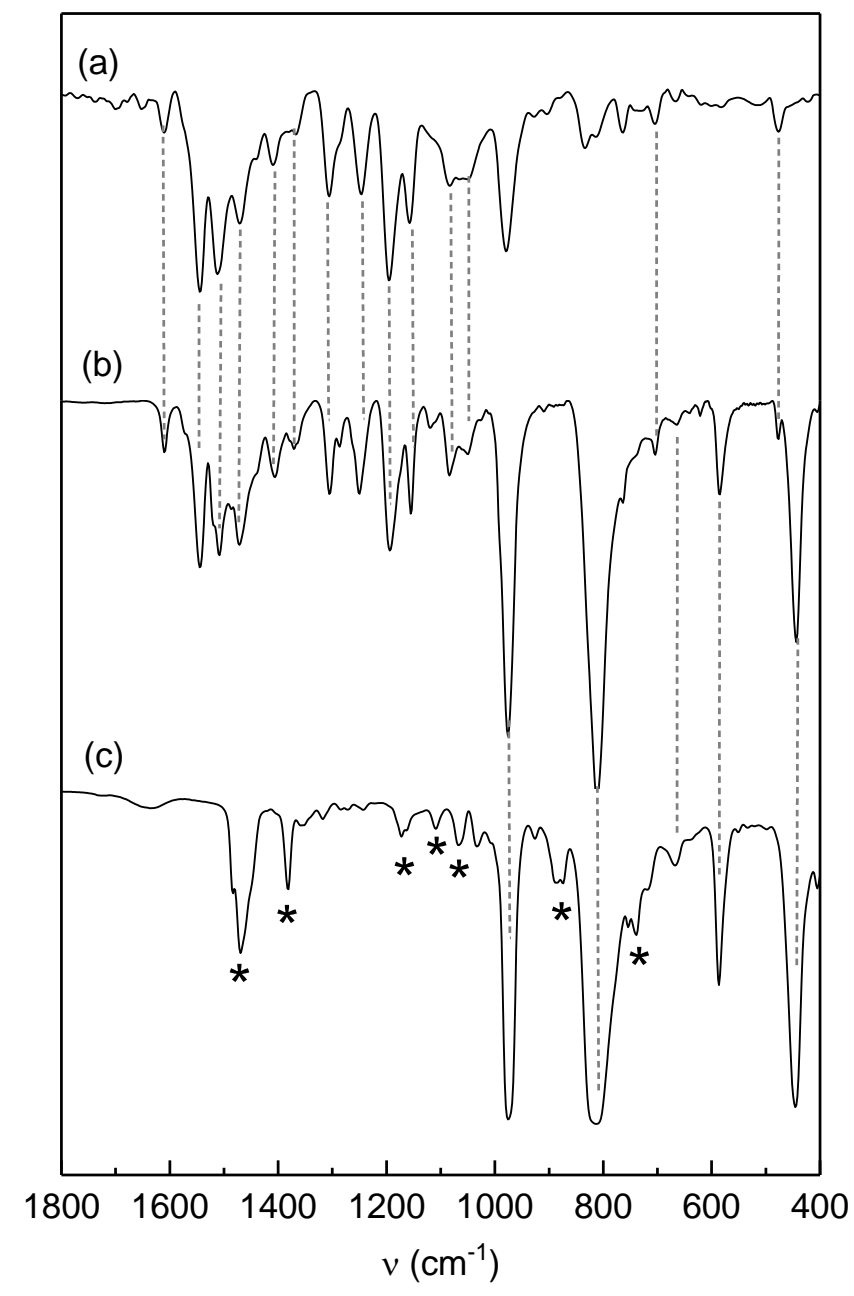


Figure S5. TGA curve of $(1)_{2}\left[\mathbf{W}_{6} \mathrm{O}_{19}\right] \cdot 2 \mathrm{CH}_{3} \mathrm{CN}$.

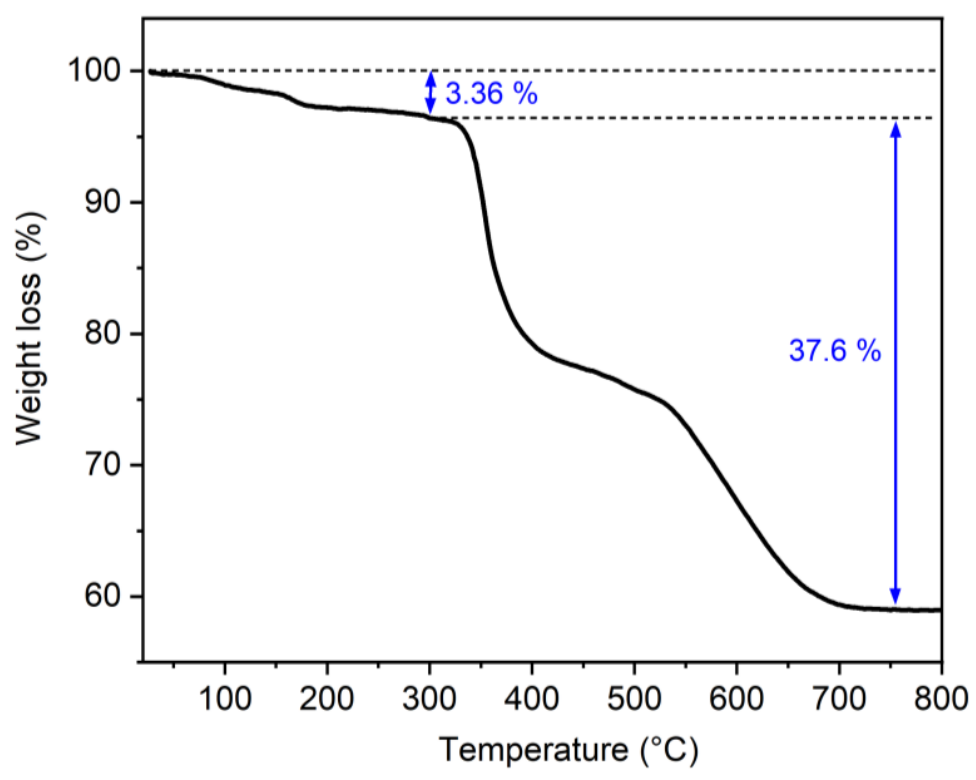

In agreement with the chemical composition, the TGA curve of $(\mathbf{1})_{2}\left[\mathbf{W}_{\mathbf{6}} \mathbf{O}_{\mathbf{1 9}}\right] \cdot \mathbf{2} \mathbf{C H}_{\mathbf{3}} \mathbf{C N}$ shows a first weight loss in the temperature range of $20-300^{\circ} \mathrm{C}$ which is attributed to the removal of the two crystallized acetonitrile molecules (theoretical weight loss of $3.4 \%$ ). The other weight losses in the temperature range of $300-750^{\circ} \mathrm{C}$ correspond to the gradual removal of the two bodipy molecules (theoretical weight loss of $37.8 \%$ ). 
Figure S6. FT-IR spectra of (a) (1)Br, and (b) (1) $)_{4}\left[\mathrm{Mog}_{8} \mathrm{O}_{26}\right] \cdot \mathbf{D M F} \cdot \mathrm{H}_{2} \mathrm{O}$. In the spectrum of (1) $)_{4}\left[\mathbf{M o}_{8} \mathbf{O}_{26}\right] \cdot \mathbf{D M F} \cdot \mathbf{H}_{2} \mathbf{O}$, the strong absorption bands in the $950-400 \mathrm{~cm}^{-1}$ range were attributed to the $\mathrm{Mo}=\mathrm{O}$ and $\mathrm{Mo}-\mathrm{O}-\mathrm{Mo}$ vibration modes of the $\beta-\left[\mathrm{Mo}_{8} \mathrm{O}_{26}\right]^{4-}$ anion. The absorption bands noticed with asterisks are attributed to the vibration modes of the crystallized DMF molecules.

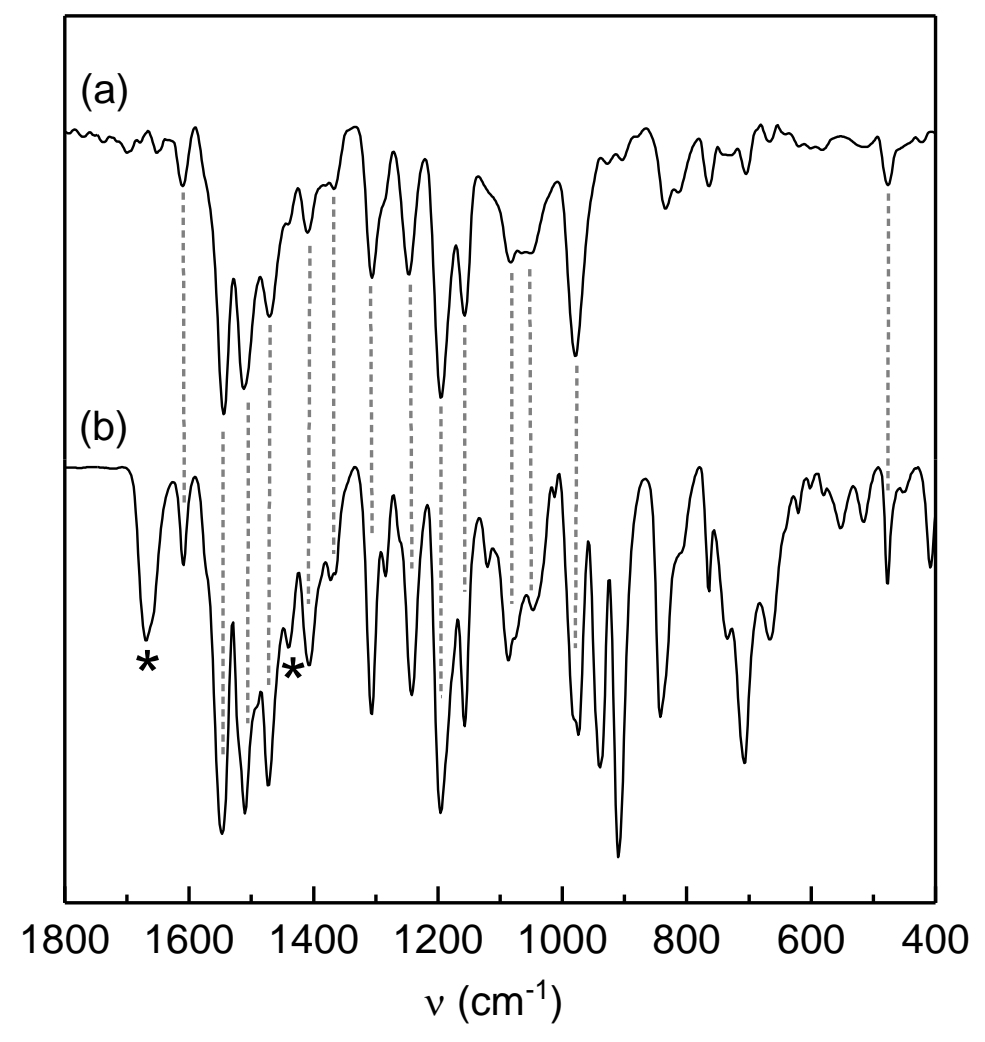


Figure S7. Molecular crystal packing in $\left(\mathbf{1}_{2}\left[\mathbf{W}_{\mathbf{6}} \mathbf{O}_{\mathbf{1 9}}\right] \cdot \mathbf{2} \mathbf{C H}_{3} \mathbf{C N}\right.$. Top: Stack of the supramolecular $\left\{(1)_{2}\left[\mathrm{~W}_{6} \mathrm{O}_{19}\right]\right\}$ ribbons along the $b$-axis (dark blue octahedra $=\mathrm{WO}_{6}$, gold sphere: oxygen, pink sphere: fluoride, blue sphere: boron, green sphere: nitrogen, grey sphere: carbon. H-atoms and acetonitrile molecules are omitted for clarity). Bottom: $\mathrm{C}-\mathrm{H} \cdots \mathrm{O}$ interactions (blue dotted lines) betwen the $\left[\mathrm{W}_{6} \mathrm{O}_{19}\right]^{2-}$ unit and the neighboring boradiazaindacene groups (ether groups and $\mathrm{H}$-atoms are omitted for clarity).

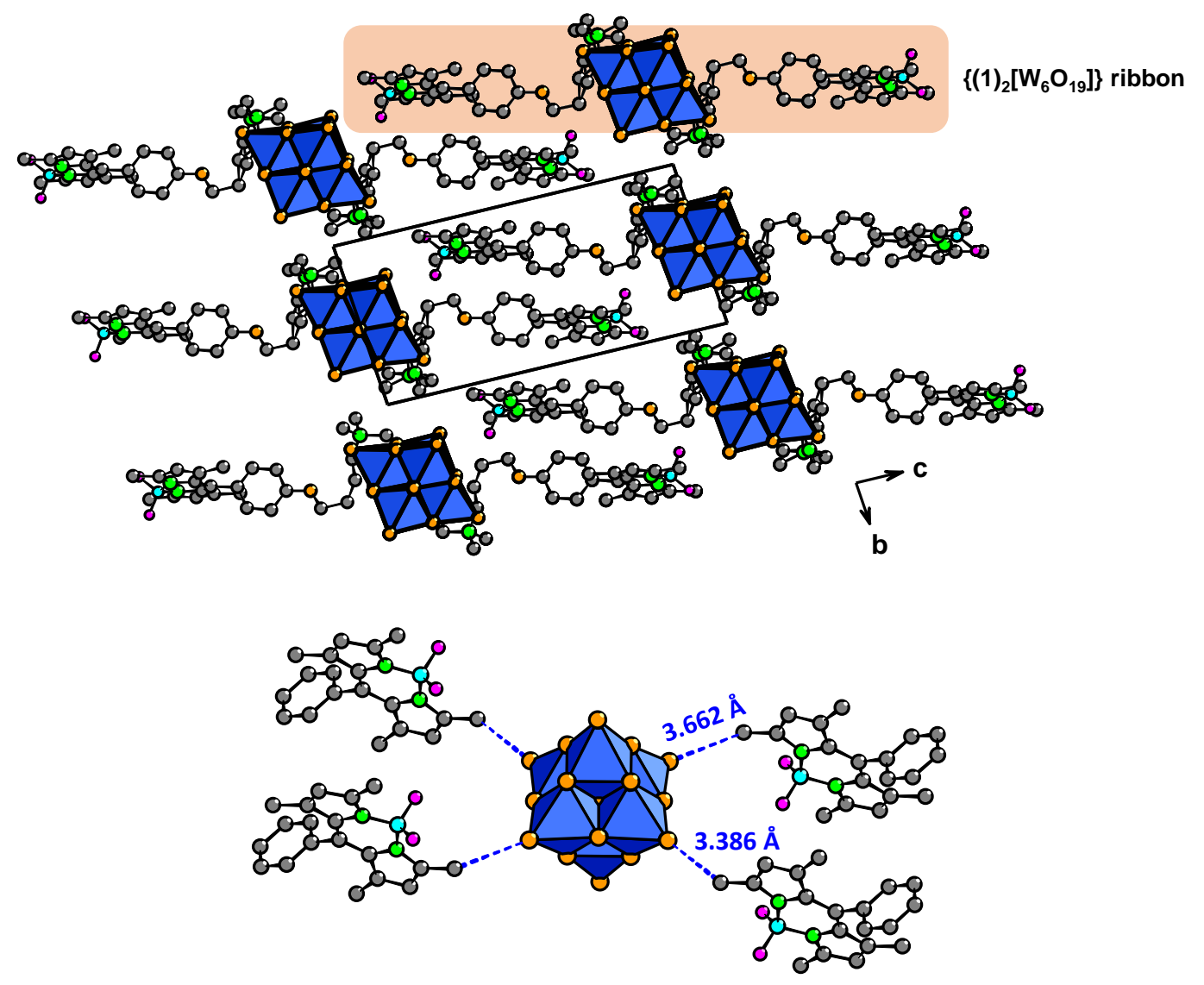


Figure S8. Molecular crystal packing in $\left(\mathbf{1}_{2}\left[\mathbf{W}_{\mathbf{6}} \mathbf{O}_{\mathbf{1 9}}\right]\right.$. Top: Representation of the $\left\{(1)_{2}\left[\mathrm{~W}_{6} \mathrm{O}_{19}\right]\right\}$ layers formed by parallel supramolecular ribbons which contain both $1^{+}$A and $1^{+}$B conformers assembled with the $\left[\mathrm{W}_{6} \mathrm{O}_{19}\right]^{2-}$ units in a herringbone-like pattern. Middle: Stack of the $\left\{(1)_{2}\left[\mathrm{~W}_{6} \mathrm{O}_{19}\right]\right\}$ layers along the $b$-axis. Bottom: C-H..O interactions (blue dotted lines) betwen the $\left[\mathrm{W}_{6} \mathrm{O}_{19}\right]^{2-}$ unit and the neighboring boradiazaindacene groups (ether groups and $\mathrm{H}$-atoms are omitted for clarity) (dark blue octahedra $=\mathrm{WO}_{6}$, gold sphere: oxygen, pink sphere: fluoride, blue sphere: boron, green sphere: nitrogen, grey sphere: carbon. H-atoms are omitted).
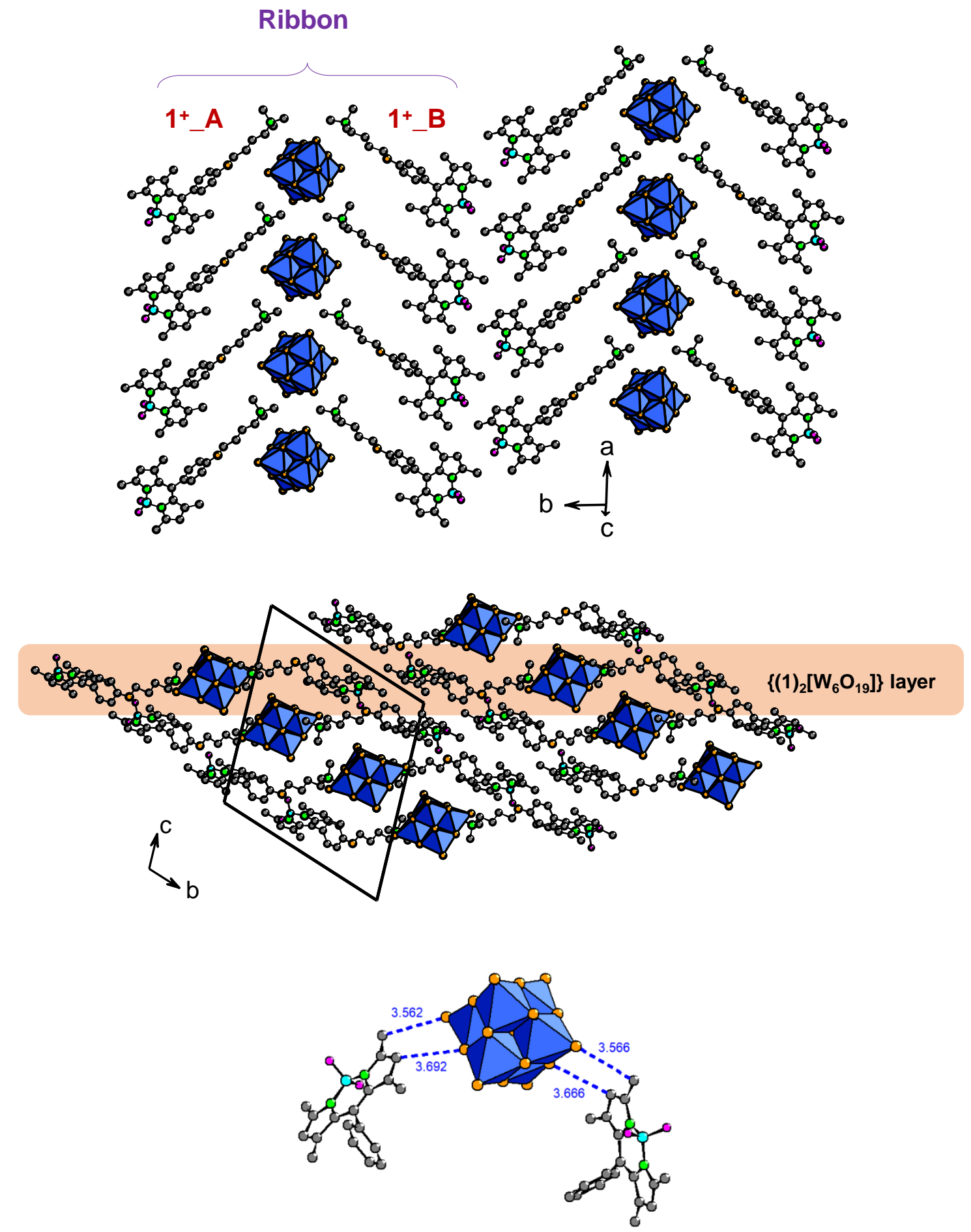
Figure S9. Top: Molecular crystal packing in $\left(\mathbf{1}_{4}\left[\mathbf{M o g}_{8} \mathbf{O}_{26}\right] \cdot \mathbf{D M F} \cdot \mathbf{H}_{2} \mathbf{O}\right.$ displaying the arrangement of the $1^{+}$molecules on both sides of the $\beta-\left[\mathrm{Mo}_{8} \mathrm{O}_{26}\right]^{4-}$ layer. (light blue octahedra $=\mathrm{MoO}_{6}$, gold sphere: oxygen, pink sphere: fluoride, blue sphere: boron, green sphere: nitrogen, grey sphere: carbon. $\mathrm{H}$-atoms are omitted). Bottom: $\mathrm{C}-\mathrm{H} \cdots \mathrm{O}$ interactions (blue dotted lines) and short $\mathrm{O} \cdots \mathrm{C}$ interactions (red dotted lines) betwen the $\beta$ - $\left[\mathrm{Mo}_{8} \mathrm{O}_{26}\right]^{4-}$ unit and the neighboring boradiazaindacene groups (ether groups and $\mathrm{H}$-atoms are omitted for clarity).
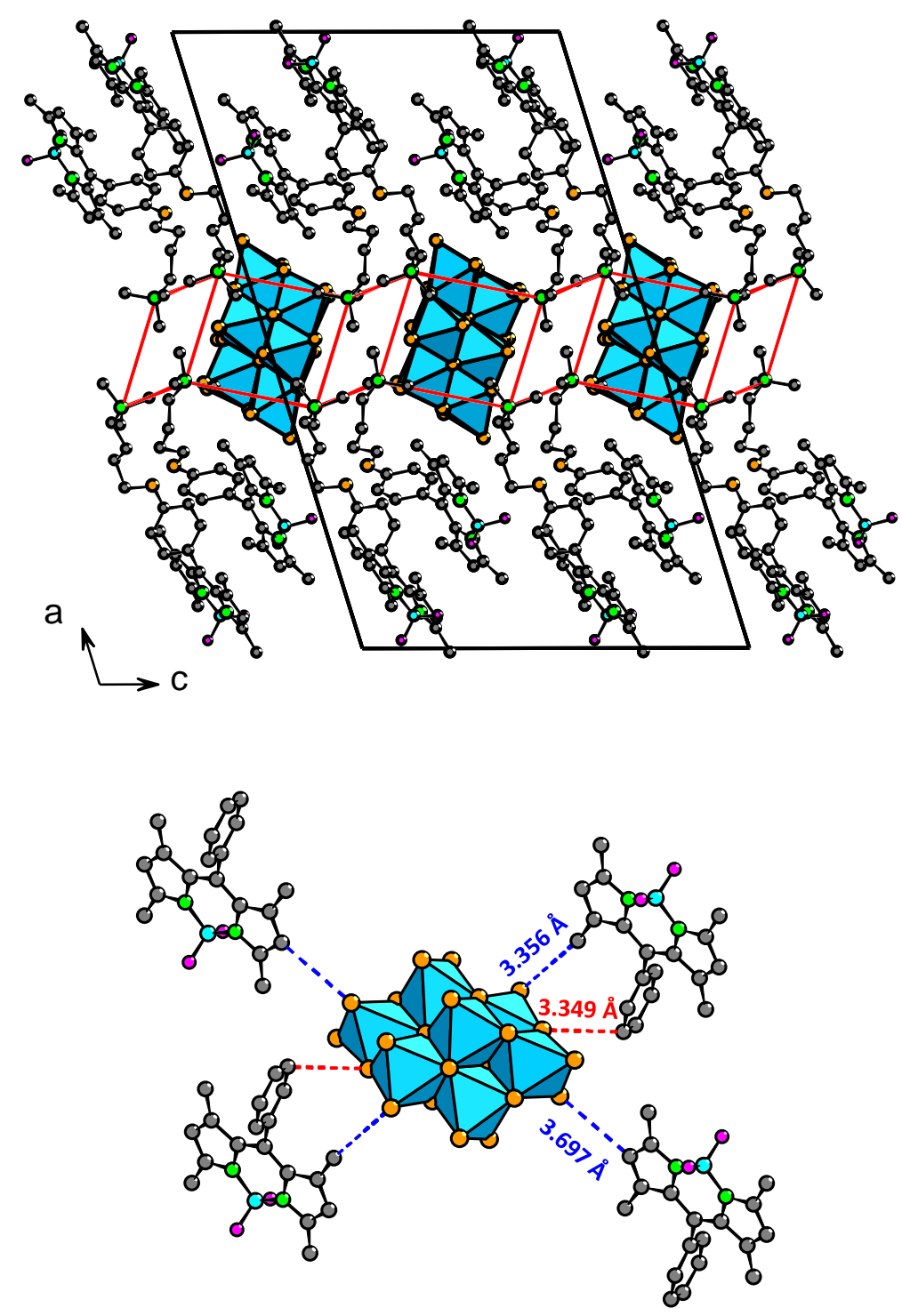
Figure S10. Top: Normalized solid-state UV-vis absorption (blue line) and PL (red line) spectra $\left(\lambda_{\mathrm{ex}}=365 \mathrm{~nm}\right)$ of $(\mathbf{1}) \mathbf{B r}$ at room temperature. Bottom: $2 \mathrm{D}$ photoluminescence excitation-emission map of (1)Br.
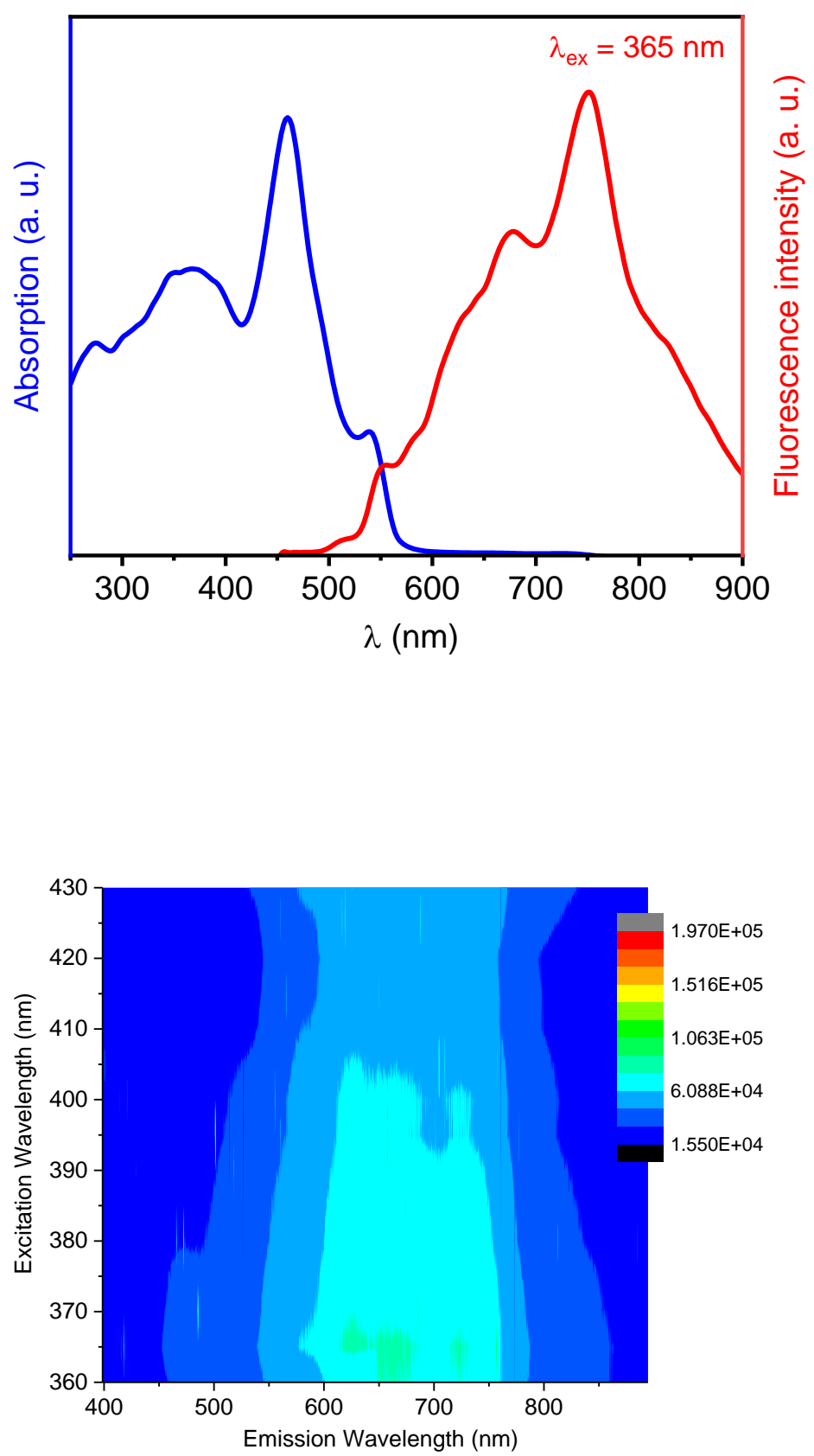
Figure S11. UV-vis absorption spectrum of (1) Br $\left(5 \cdot 10^{-5} \mathrm{~mol} / \mathrm{L}\right)$ in $\mathrm{CH}_{3} \mathrm{CN}$.

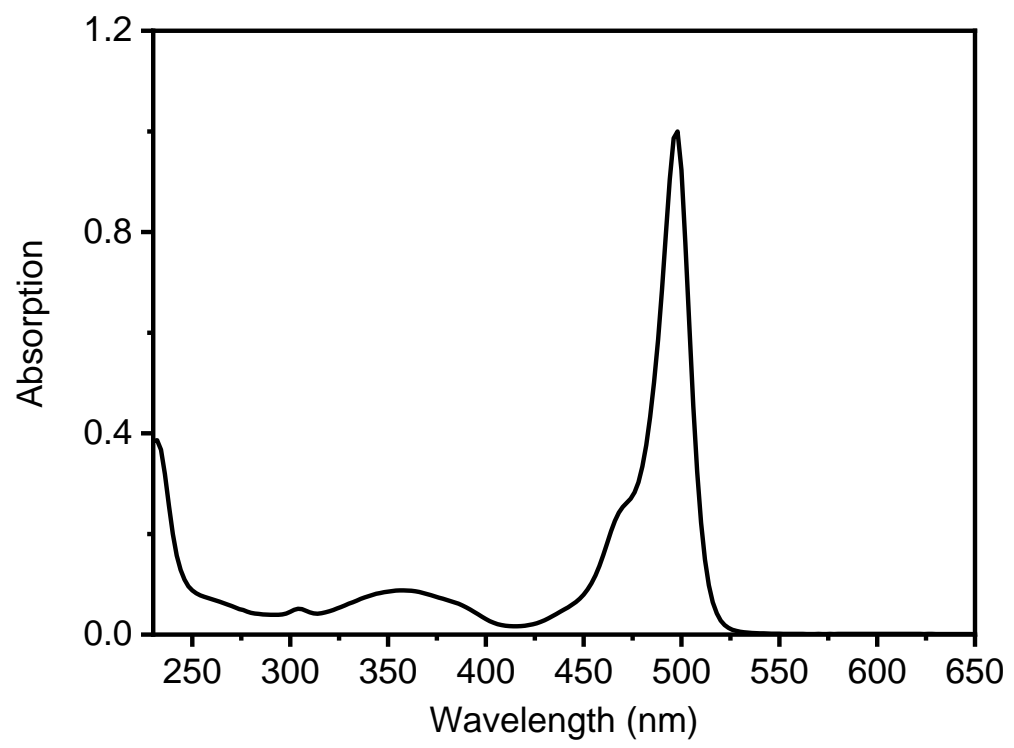


Figure S12. Left panel: Instrument response function (IRF) of the time-resolved photoluminescence setup captured with the $400 \mathrm{~nm}$ 100-fs laser trace on a $1 \mathrm{~ns}$ time window (a). The thick line is a Gaussian fit of the profile. FWHM $=35$ ps. Zero-time delay corresponds to the beginning of the streak camera sweep.

Right panel: time-resolved photoluminescence spectrum integrated on a $1 \mathrm{~ns}$ time window (b) and spectrally-integrated emission kinetics (c) of $(\mathbf{1}) \mathbf{B r}\left(\lambda_{\mathrm{ex}}=400 \mathrm{~nm}\right)$. The thin line is a fit to the data. The transient signals were spectrally dispersed into a Princeton Instruments SP2300 imaging Acton spectrograph specially fitted for the streak camera. ${ }^{\text {S5 }}$
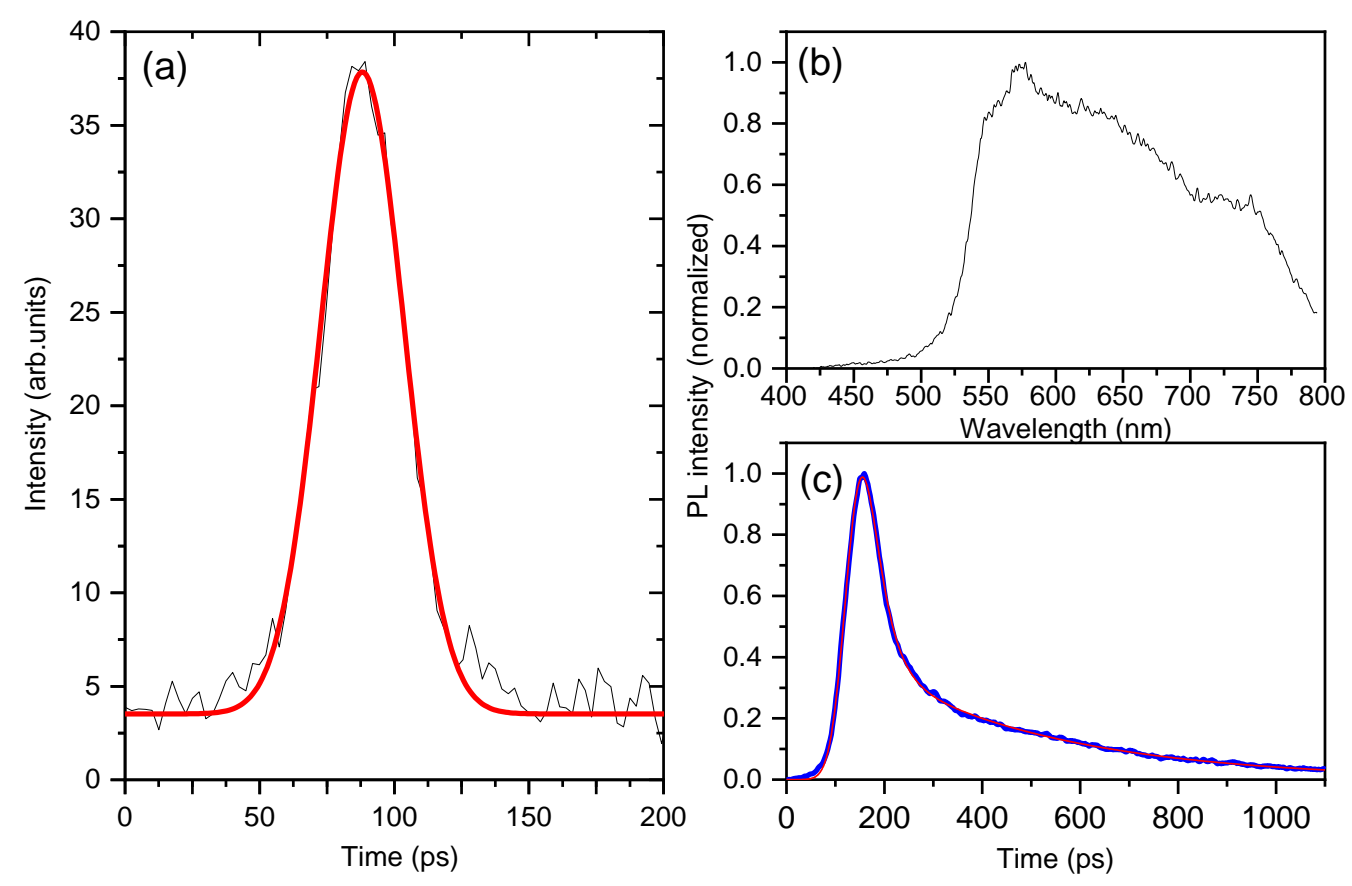
Figure S13. CIE chromaticity diagram for (1)Br excited at $365 \mathrm{~nm}$.

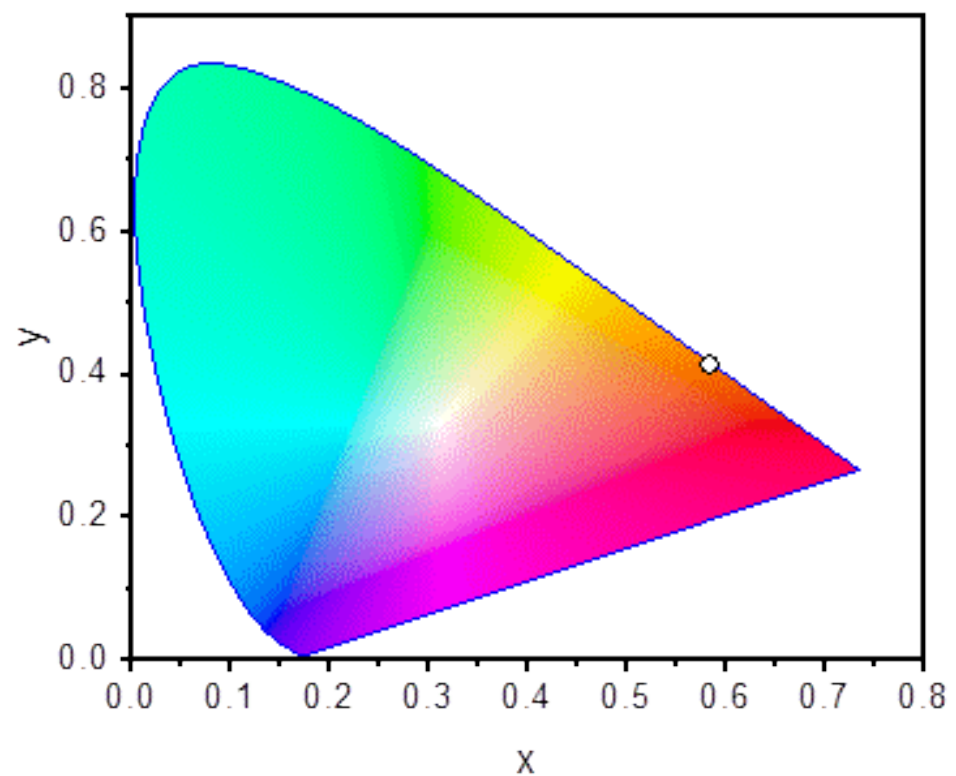


Figure S14. Room-temperature steady-state PL excitation spectra of $(\mathbf{1})_{2}\left[\mathbf{W}_{6} \mathbf{O}_{19}\right] \cdot 2 \mathbf{C H}_{3} \mathbf{C N}$ (blue line), (1) $)_{2}\left[\mathbf{W}_{6} \mathbf{O}_{19}\right]$ (black line) and (1) $\left[\mathbf{M o g}_{\mathbf{8}} \mathbf{O}_{\mathbf{2 6}}\right] \cdot \mathbf{D M F} \cdot \mathbf{H}_{2} \mathbf{O}$ (red line) monitored at $\lambda_{\mathrm{ex}}$ $=753 \mathrm{~nm}$.

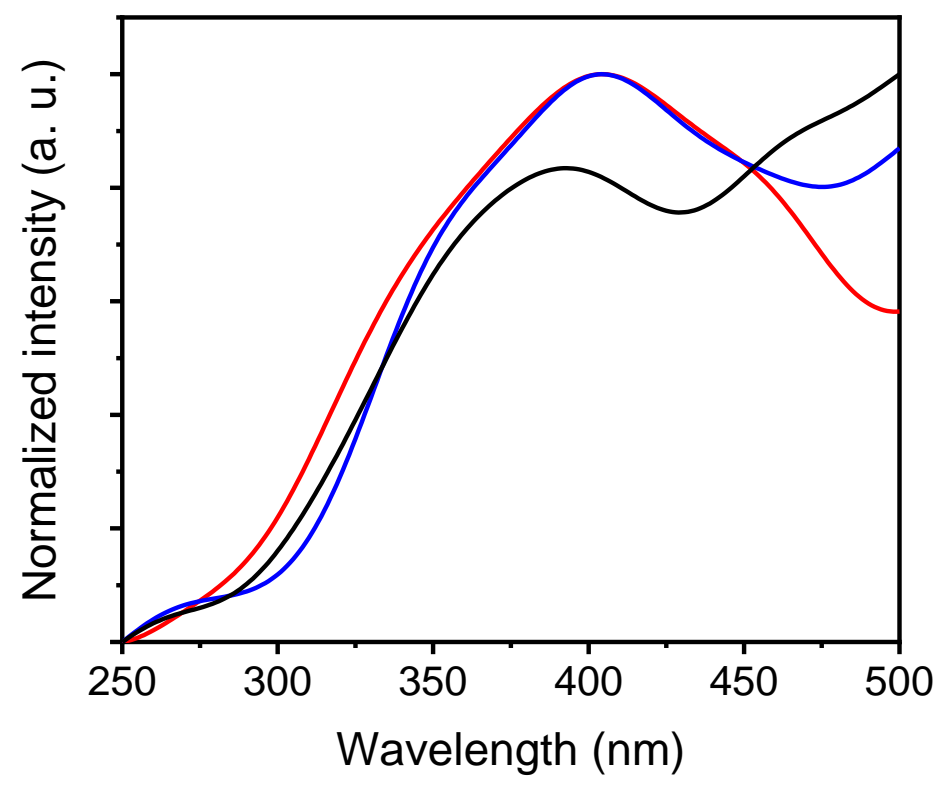


Figure S15. Time-resolved photoluminescence spectra (a) and spectrally-integrated emission kinetics (b) of (1) ${ }_{2}\left[\mathbf{W}_{6} \mathbf{O}_{19}\right] \cdot \mathbf{2} \mathbf{C H}_{3} \mathbf{C N},(\mathbf{1})_{2}\left[\mathbf{W}_{6} \mathbf{O}_{19}\right]$ and $(\mathbf{1})_{4}\left[\mathbf{M o g}_{8} \mathbf{O}_{26}\right] \cdot \mathbf{D M F} \cdot \mathbf{H}_{2} \mathbf{O}\left(\lambda_{\text {ex }}=400\right.$ $\mathrm{nm})$. The spectra of (1) ${ }_{4}\left[\mathbf{M o g}_{8} \mathbf{O}_{26}\right] \cdot \mathbf{D M F} \cdot \mathbf{H}_{2} \mathbf{O}$ and other compounds have been integrated on a $10 \mu \mathrm{s}$ and on a $1 \mathrm{~ns}$ time window, respectively. Thin lines are fit to the data. Zero-time delay corresponds to the beginning of the streak camera sweep.

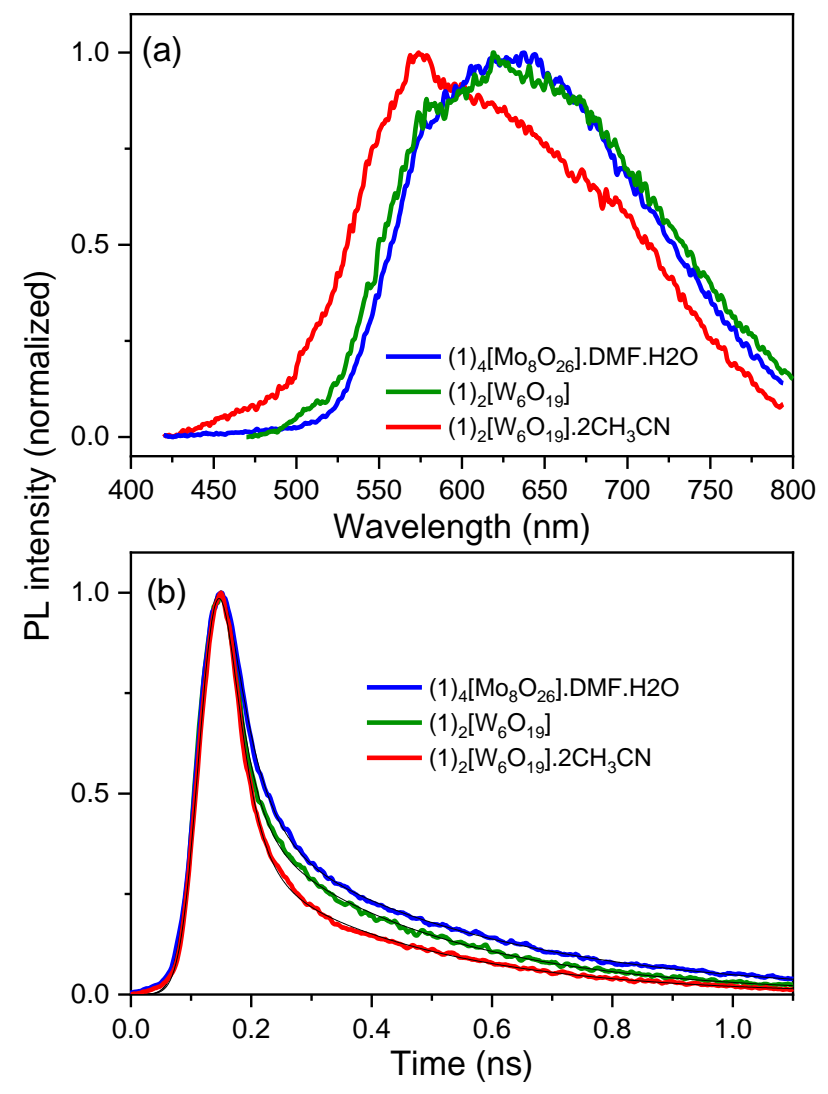


Figure S16. CIE chromaticity diagram for $\left(\mathbf{1}_{2}\left[\mathrm{~W}_{6} \mathrm{O}_{19}\right], \quad(\mathbf{1})_{2}\left[\mathrm{~W}_{6} \mathrm{O}_{19}\right] \cdot \mathbf{2} \mathrm{CH}_{3} \mathrm{CN}\right.$ and (1) $)_{4}\left[\mathbf{M o}_{8} \mathbf{O}_{26}\right] \cdot \mathbf{D M F} \cdot \mathbf{H}_{2} \mathbf{O}$ excited at $365 \mathrm{~nm}$.

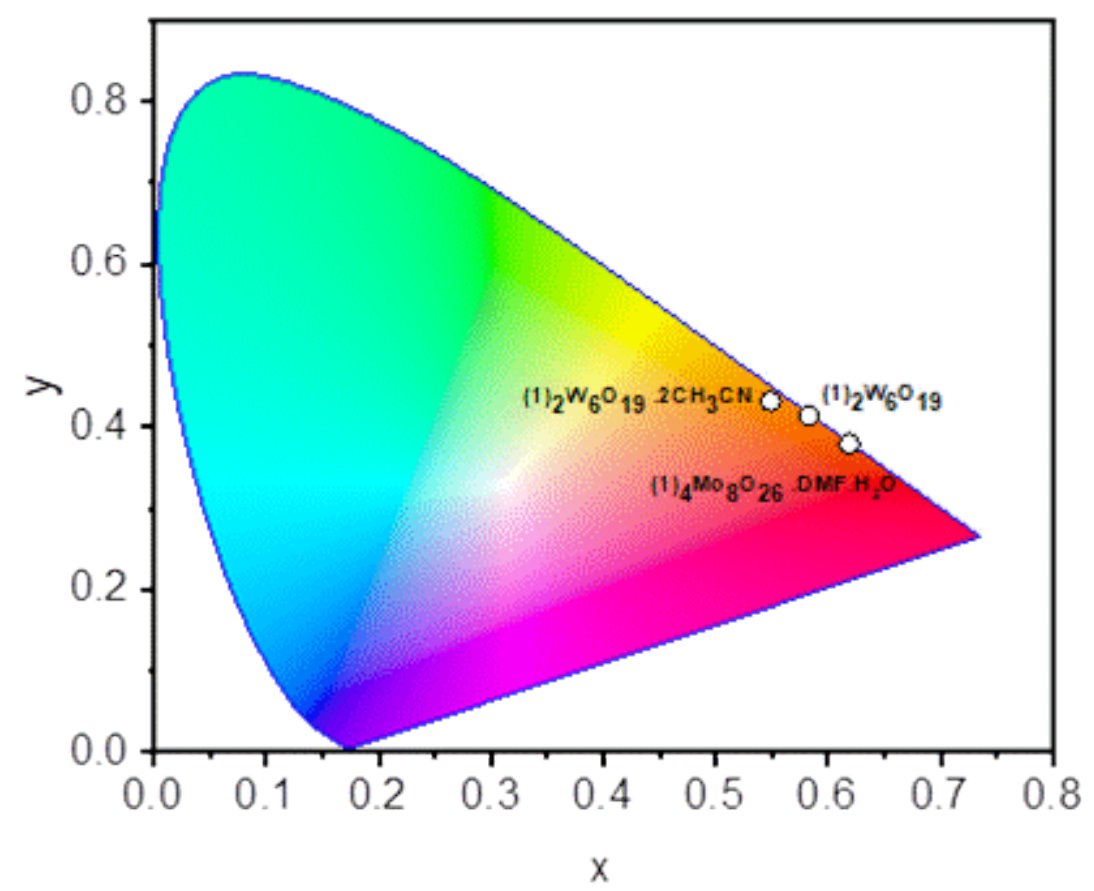


Table S1. Selected reported strategies to improve the solid-state fluorescence of BODIPY derivatives.

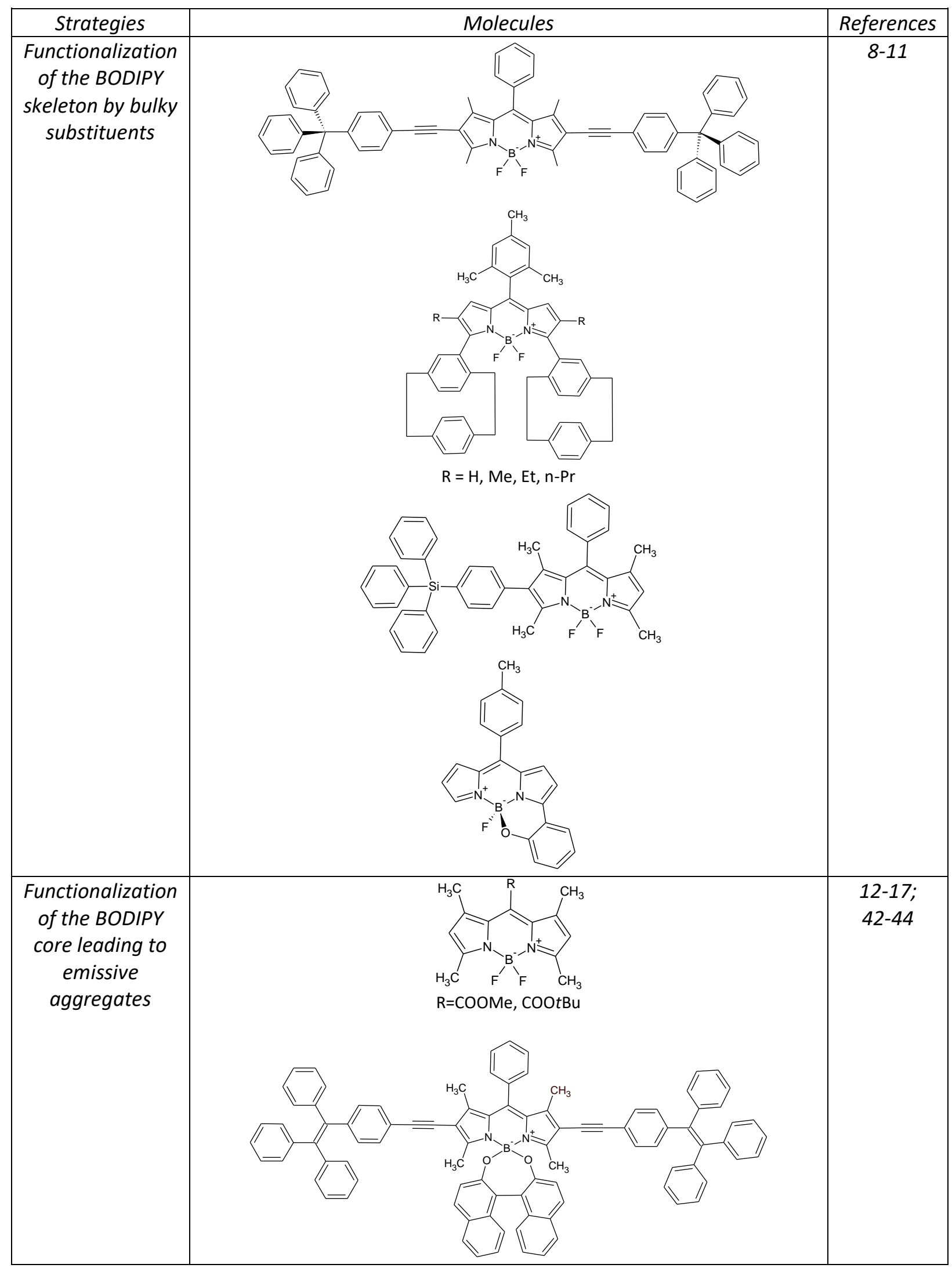




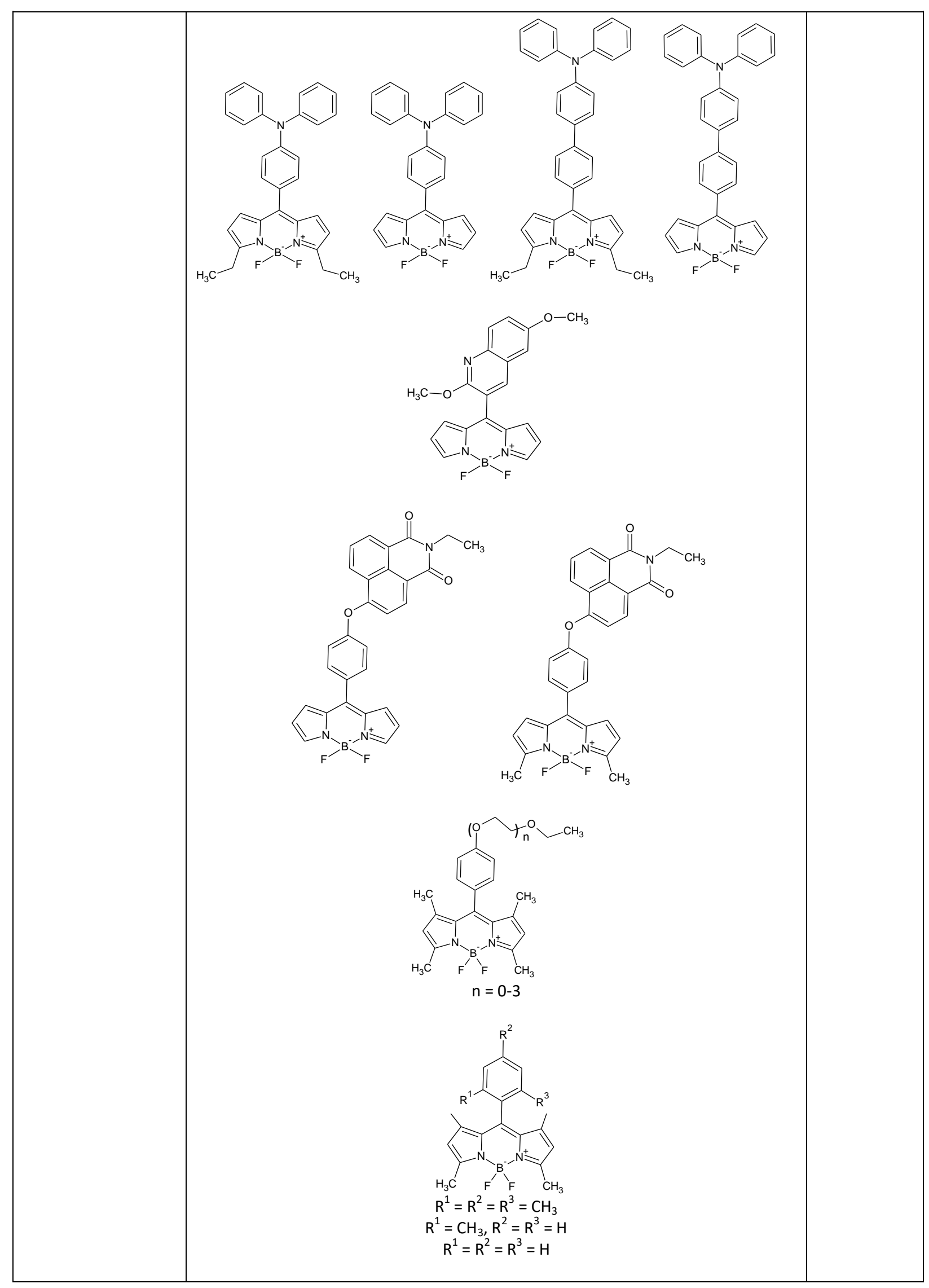




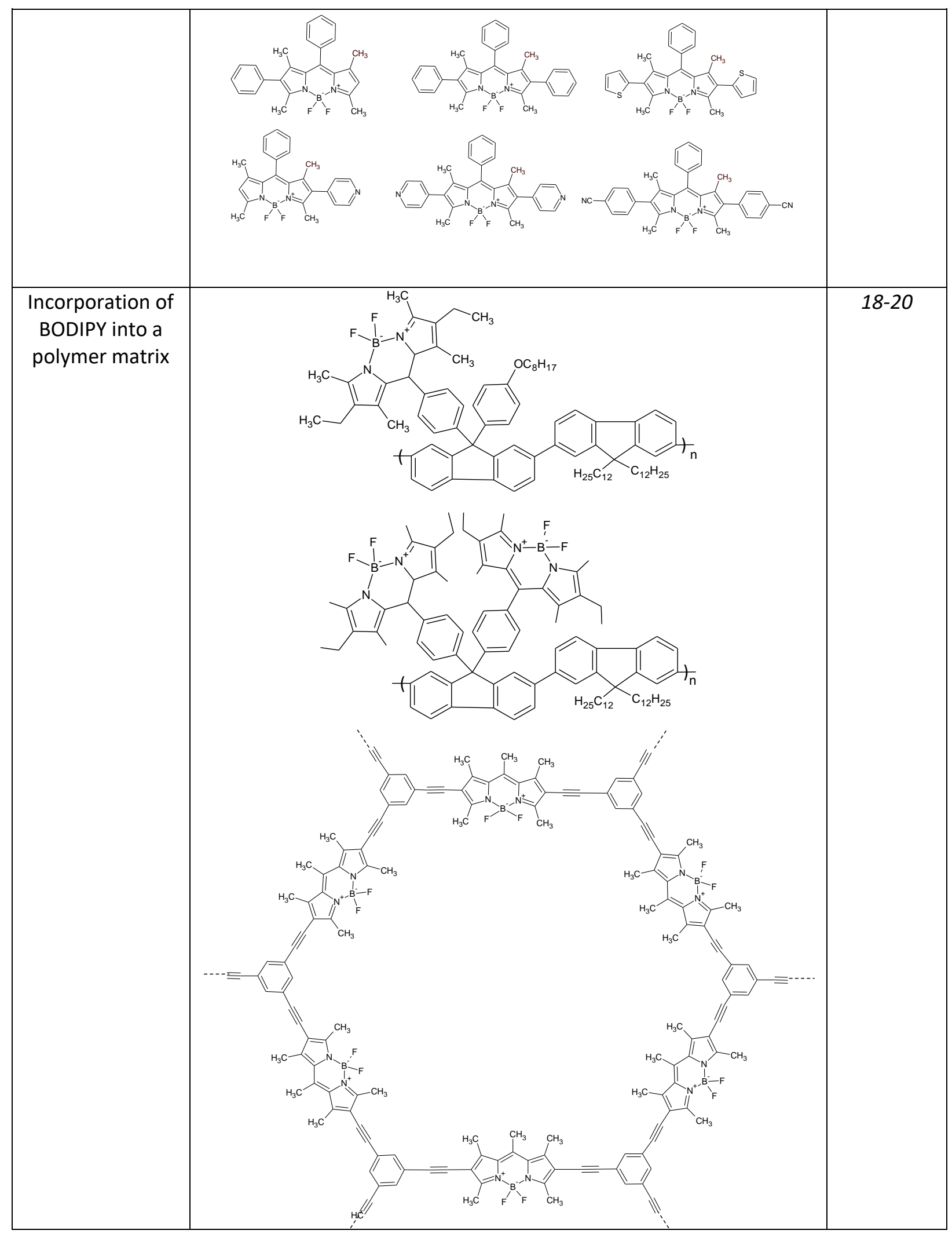




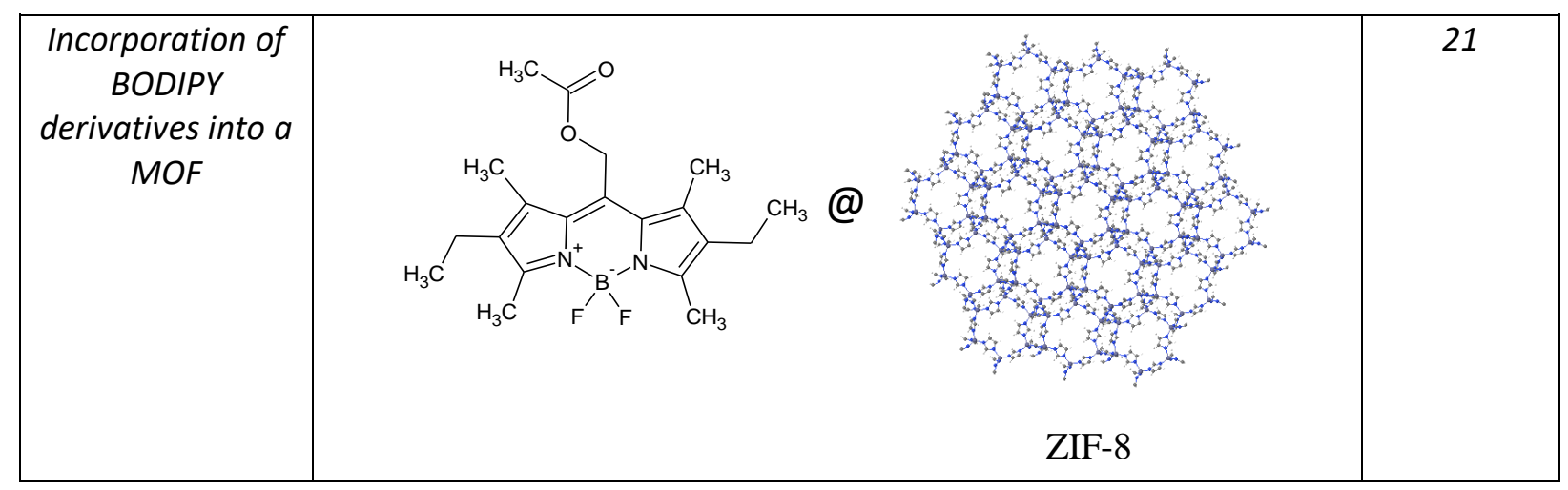


Table S2. Crystal data and structure refinement for $(\mathbf{1})_{2}\left[\mathbf{W}_{6} \mathbf{O}_{19}\right],(\mathbf{1})_{2}\left[\mathbf{W}_{6} \mathbf{O}_{19}\right] \cdot \mathbf{2} \mathrm{CH}_{3} \mathbf{C N}$ and (1) ${ }_{4}\left[\mathrm{Mog}_{8} \mathrm{O}_{26}\right] \cdot \mathrm{DMF} \cdot \mathrm{H}_{2} \mathrm{O}$.

\begin{tabular}{|c|c|c|c|}
\hline & $(1)_{2}\left[W_{6} O_{19}\right]$ & $(1)_{2}\left[\mathrm{~W}_{6} \mathrm{O}_{19}\right] \cdot 2 \mathrm{CH}_{3} \mathrm{CN}$ & $(1)_{4}\left[\mathrm{Mo}_{8} \mathrm{O}_{26}\right] \cdot \mathrm{DMF} \cdot \mathrm{H}_{2} \mathrm{O}$ \\
\hline Empirical formula & $\mathrm{C}_{52} \mathrm{H}_{70} \mathrm{~B}_{2} \mathrm{~F}_{4} \mathrm{~N}_{6} \mathrm{O}_{21} \mathrm{~W}_{6}$ & $\mathrm{C}_{56} \mathrm{H}_{76} \mathrm{~B}_{2} \mathrm{~F}_{4} \mathrm{~N}_{8} \mathrm{O}_{21} \mathrm{~W}_{6}$ & $\mathrm{C}_{107} \mathrm{H}_{149} \mathrm{~B}_{4} \mathrm{~F}_{8} \mathrm{~N}_{13} \mathrm{O}_{32} \mathrm{Mo}_{8}$ \\
\hline Formula weight / g & 2315.86 & 2397.96 & 3090.13 \\
\hline Crystal system & Triclinic & Triclinic & Monoclinic \\
\hline Space group & $P-1$ & $P-1$ & $P 2_{1} / \mathrm{c}$ \\
\hline$a / \AA$ & $9.5249(5)$ & $9.5859(5)$ & $32.046(3)$ \\
\hline$b / \AA$ & $18.2995(10)$ & $10.3565(6)$ & 10.9153(9) \\
\hline$c / \AA$ & $20.7250(11)$ & 19.4943(11) & $19.2184(16)$ \\
\hline$\alpha /{ }^{\circ}$ & $108.153(3)$ & $85.090(2)$ & 90 \\
\hline$\beta /^{\circ}$ & $98.868(3)$ & $89.840(2)$ & $107.068(3)$ \\
\hline$\gamma /{ }^{\circ}$ & $94.805(3)$ & $64.540(2)$ & 90 \\
\hline$V / \AA^{3}$ & $3358.0(3)$ & $1739.72(17)$ & $6426.4(9)$ \\
\hline$Z$ & 2 & 1 & 2 \\
\hline$\rho_{\text {calc }} / \mathrm{g} \mathrm{cm}^{-3}$ & 2.290 & 2.289 & 1.597 \\
\hline$\mu / \mathrm{mm}^{-1}$ & 10.32 & 9.96 & 0.84 \\
\hline Data / Parameters & $9600 / 823$ & $10188 / 471$ & $18856 / 818$ \\
\hline$R_{\text {int }}$ & 0.042 & 0.038 & 0.045 \\
\hline GOF & 1.25 & 1.08 & 1.11 \\
\hline$R(>2 \sigma(I))$ & $\begin{array}{l}0.081 \\
0.192\end{array}$ & $\begin{array}{l}R_{1}^{a}=0.036 \\
w R_{2}^{b}=0.110\end{array}$ & $\begin{array}{l}0.038 \\
0.095\end{array}$ \\
\hline
\end{tabular}


Table S3. Photoluminescence lifetimes determined from bi-exponential fits including convolution with the IRF for (1)Br, $\left(\mathbf{1}_{2}\left[\mathbf{W}_{6} \mathbf{O}_{19}\right], \quad\left(\mathbf{1}_{2}\left[\mathbf{W}_{6} \mathbf{O}_{19}\right] \cdot \mathbf{2} \mathrm{CH}_{3} \mathbf{C N}\right.\right.$ and (1) $)_{4}\left[\mathrm{Mo}_{8} \mathrm{O}_{26}\right] \cdot \mathrm{DMF} \cdot \mathrm{H}_{2} \mathrm{O} . R^{2}$ is the coefficient of determination, and $R$ the coefficient of correlation. $A_{1}, A_{2}, P_{1}, P_{2}$ are defined below. Measurements were carried out with a streak camera.

\begin{tabular}{|c|c|c|c|c|c|c|c|c|c|c|}
\hline Sample & $\begin{array}{l}\lambda_{\text {exc }} \\
(\mathrm{nm})\end{array}$ & $\begin{array}{l}\lambda_{\mathrm{em}} \\
(\mathrm{nm})\end{array}$ & $\begin{array}{l}\tau_{1} \\
(\mathrm{ps})\end{array}$ & $\begin{array}{l}\tau_{2} \\
(\mathrm{ps})\end{array}$ & $\tau_{\text {mean }}$ & $A_{1}$ & $A_{2}$ & $P_{1}$ & $P_{2}$ & $R^{2}$ \\
\hline (1) $\mathrm{Br}$ & 400 & $\begin{array}{l}573, \\
734\end{array}$ & 31.7 & 380 & 258.6 & 1.7156 & 0.2671 & 0.349 & 0.651 & 0.99903 \\
\hline$(1)_{4}\left[\mathrm{Mo}_{8} \mathrm{O}_{26}\right] \cdot \mathrm{DMF} \cdot \mathrm{H}_{2} \mathrm{O}$ & 400 & 622 & 42.1 & 388 & 271.5 & 1.4297 & 0.3055 & 0.407 & 0.593 & 0.99929 \\
\hline$(\mathbf{1})_{2}\left[\mathrm{~W}_{6} \mathrm{O}_{19}\right]$ & 400 & $\begin{array}{l}578, \\
618\end{array}$ & 29.8 & 315.5 & 218.7 & 1.6972 & 0.3130 & 0.339 & 0.661 & 0.99898 \\
\hline$(1)_{2}\left[\mathrm{~W}_{6} \mathrm{O}_{19}\right] \cdot 2 \mathrm{CH}_{3} \mathrm{CN}$ & 400 & 572 & 28.9 & 299 & 185.5 & 1.7389 & 0.2319 & 0.420 & 0.580 & 0.99914 \\
\hline
\end{tabular}

The decaying population is defined as $n=A_{1} n_{1}+A_{2} n_{2}$, where $A_{1}$ and $A_{2}$ are PL intensity amplitudes from levels 1 and 2, respectively. For the mean luminescence lifetime, we consider the intensity-weighted lifetime $\tau_{\text {mean }}$ below rather than the amplitude-weighted one:

$$
\tau_{\text {mean }}=\frac{A_{1} \tau_{1}^{2}+A_{2} \tau_{2}^{2}}{A_{1} \tau_{1}+A_{2} \tau_{2}}
$$

The yield of PL intensity for each exponential process is given by:

$$
P_{i}=\frac{A_{i} \tau_{i}}{\sum_{j} A_{j} \tau_{j}}
$$

\section{References}

(S1) Kubelka, P.; Munk, F. Ein Beitrag Zur Optik Der Farbanstriche. Z. Techn. Physik 1931, 12, 593-601.

(S2) Sheldrick, G. M. Sheldrick, G. M.SADABS, Program for Scaling and Correction of Area Detector Data; University of Göttingen: Göttingen, Germany, 1997. SADABS Program Scaling Correct. Area Detect. Data Univ. Gött. Gött. Ger. 1997.

(S3) Blessing, R. H. An Empirical Correction for Absorption Anisotropy. Acta Crystallogr. Sect. A 1995, 51, 33-38.

(S4) Sheldrick, G. M. SHELX-TL, Software Package for the CrystalStruc-Ture Determination, Siemens Analytical X-Ray Instrument Divi-Sion,Version 5.03; Bruker AXS Inc.: Madison, WI. SHELX-TL Softw. Package CrystalStruc-Ture Determ. Siemens Anal. XRay Instrum. Divi-Sionversion 503 Bruker AXS Inc Madison WI 1994.

(S5) Massuyeau F.; Perry D.L.; Kalashnyk N.; Faulques E. Spectroscopic markers for uranium(VI) phosphates. Part II: the use of time-resolved photoluminescence. RSC Adv., 2017, 7, 919-926. 